\title{
Intestinal permeability in kwashiorkor
}

\author{
D R Brewster, M J Manary, I S Menzies, E V O’Loughlin, R L Henry
}

College of Medicine, University of Malawi, Blantyre, Malawi D R Brewster

Washington University School of Medicine, St Louis, USA M J Manary

Department of Clinical Biochemistry, King's College Medical School, London I S Menzies

New Children's Hospital, University of Sydney, Westmead, Australia E V O'Loughlin

Faculty of Medicine and Health Sciences, University of Newcastle, Australia R L Henry

Correspondence to: Dr David Brewster, Flinders University and Maternal and Child Health, Royal Darwin Hospital, PO Box 41326 , Casuarina, NT 0811, Australia.

Accepted 16 September 1996

\begin{abstract}
Intestinal permeability can be assessed non-invasively using the lactuloserhamnose (L-R) test, which is a reliable measure of small intestinal integrity.

Aims-To determine risk factors for abnormal intestinal permeability in kwashiorkor, and to measure changes in L-R ratios with inpatient rehabilitation.

Design-A case-control study of 149 kwashiorkor cases and 45 hospital controls. The L-R test was adapted to study kwashiorkor in Malawi, with testing at weekly intervals during nutritional rehabilitation. Urine sugars were measured by thin layer chromatography in London.
\end{abstract}

Results-The initial geometric mean L-R ratios $(\times 100)$ (with $95 \%$ confidence interval) in kwashiorkor were 17.3 (15.0 to 19.8) compared with 7.0 (5.6 to 8.7) for controls. Normal ratios are $<5$, so the high ratios in controls indicate tropical enteropathy syndrome. Abnormal permeability in kwashiorkor was associated with death, oliguria, sepsis, diarrhoea, wasting and young age. Diarrhoea and death were associated with both decreased L-rhamnose absorption (diminished absorptive surface area) and increased lactulose permeation (impaired barrier function) whereas nutritional wasting affected only L-rhamnose absorption. Despite clinical recovery, mean $L-R$ ratios improved little on treatment, with mean weekly ratios of 16.3 (14.0 to 19.0$), 13.3$ (11.1 to 15.9 ) and 14.4 (11.0 to 18.8$)$.

Conclusion-Abnormal intestinal permeability in kwashiorkor correlates with disease severity, and improves only slowly with nutritional rehabilitation.

(Arch Dis Child 1997;76:236-241)

Keywords: kwashiorkor; intestinal permeability; Africa.

Kwashiorkor is the most common form of severe malnutrition in Malawi, accounting for $75 \%$ of all admissions to nutritional rehabilitation centres in the southern region. It has a case fatality rate of over $30 \%$ in urban treatment centres, which has changed little over recent decades despite an overall fall in childhood mortality in those under 5 years. ${ }^{12}$ An important contributor to the poor response of kwashiorkor to treatment is the degree of intestinal mucosal damage, which requires the use of a low energy and protein diet during the ini- tial phase of treatment. ${ }^{3}$ Measures which quicken recovery of mucosal integrity should result in improved outcomes and shorter inpatient rehabilitation. Intestinal permeability testing with the lactulose-rhamnose (L-R) test is a good indicator of mucosal integrity and gives reliable repeatable measurements to evaluate therapeutic interventions. ${ }^{4-11}$

Permeability refers to the intestinal mucosa's capacity to allow molecules to traverse it by unmediated diffusion. In this study, we measured it non-invasively by the L-R test. The sugars lactulose and L-rhamnose are polar and non-lipid soluble probes which permeate by aqueous pathways and have molecular weights of 342 and 164, respectively. Mucosal damage tends to reduce L-rhamnose absorption due to less absorptive surface area and increase lactulose permeation due to impaired barrier function. ${ }^{5}$ The basic mechanisms of sugar probe permeation are still poorly understood, but have been reviewed recently. ${ }^{12}$ The use of lactulose and L-rhamnose as probe markers assumes that they are not significantly metabolised and are quantitatively excreted unmodified in urine after absorption. The use of a ratio minimises extraneous factors such as intestinal motility, renal function, and incomplete urine collection. ${ }^{13}$ Thus, the differential absorption of lactulose and L-rhamnose is a sensitive index of mucosal integrity due to a loss of absorptive capacity and/or breaches of the mucosal barrier. $^{14}$

The aim of this study was to assess the degree of intestinal damage in kwashiorkor using the L-R test, to identify risk factors for abnormal permeability, and to measure changes in permeability with inpatient nutritional rehabilitation.

\section{Patients and methods}

PATIENTS

The study was carried out at Queen Elizabeth Central Hospital in Blantyre, Malawi between January and September 1995. Children admitted with kwashiorkor (including marasmic kwashiorkor) during the study period were eligible for entry into the study. Kwashiorkor was diagnosed clinically on the basis of nutritional oedema, with other causes of oedema such as nephrosis, nephritis, and severe malarial anaemia excluded. The experimental group of 149 children for permeability studies was selected from a total of 606 kwashiorkor admissions during the study period $(24.6 \%)$ of whom 553 remained in hospital for at least five days. In 
selecting patients for a permeability study, there was an explicit bias to boys (from whom it is easier to collect urine), to those admitted just before the two study nights per week, and to those likely to survive for repeat testing. These selection criteria were applied consistently throughout the study period by the same research assistant. Children with diarrhoea were rehydrated before permeability testing. Controls were selected from hospitalised children without diarrhoea or wasting, who were recovering from pneumonia, soft tissue infections, or chronic diseases such as tuberculosis or osteomyelitis. Children with other diseases or treatments which are known to affect permeability were excluded from the study (for example severe malaria, iron deficiency anaemia, non-steroidal anti-inflammatory drugs).

A parent or guardian of children in the study was administered a field tested questionnaire about household water supply, sanitation, hygiene practices, health, and socioeconomic status. This was developed into a score which increased proportionately with higher socioeconomic status. Weights and recumbent lengths of subjects were measured by a single trained research assistant using standard techniques on a Salter hanging scale and locally made stadiometer. Although measurements were recorded to the nearest $0.1 \mathrm{~kg}$ and $0.1 \mathrm{~cm}$, we found from repeat measurements that there was digit preference and a tolerance level closer to $0.5 \mathrm{~cm}$ for height. Since all children had recumbent length measured, because it is more reproducible in sick children, a correction factor of $1.5 \mathrm{~cm}$ was subtracted from the length measurement of children $>24$ months to approximate height for the National Center for Health Statistics (NCHS) standard. ${ }^{15}$

After standard treatment, all kwashiorkor cases were given routine antibiotics (cotrimoxazole) for at least five days, and supplements of minerals, micronutrients, and vitamins. Out of the 149 children with kwashiorkor in whom permeability testing was done, 76 were treated with a milk based diet, 64 with an exclusively maize based (milk free) diet, and nine with both diets over a changeover period. Details of the diets are given in the companion paper. ${ }^{16}$ Clinical sepsis was defined as fever, respiratory distress, a change in mental status, shock or any abrupt deterioration in condition.
Consent for enzyme linked immunosorbent assay (ELISA) testing for HIV infection after precounselling was often refused, making it impossible to test all malnourished children. Although there were only 23 positive tests out of 50, our estimated prevalence of HIV infection in study patients from a clinical protocol was 43 children (29\%). HIV infected patients were not excluded from the study because, like tuberculosis and chronic diarrhoea, it is part of the clinical spectrum of kwashiorkor in Africa.

L-R TEST

Study children drank $100 \mathrm{ml}$ of an isotonic solution of lactulose $5 \mathrm{~g}$ (as Duphalac) and L-rhamnose $1 \mathrm{~g}$ (Sigma) in the evening and all urine passed overnight was collected, using 24 hour urine bags with a special skin adhesive technique for incontinent children. Merthiolate (minimum $10 \mathrm{mg} / 100 \mathrm{ml}$ ) was added to the urine collector to prevent bacterial degradation of the sugars. Study children stayed overnight in a special ward where the nurse had no other responsibilities, and recorded the time and volume of urine voided. Two $2 \mathrm{ml}$ specimens were frozen for laboratory measurement of lactulose, L-rhamnose, lactose, and urea. Children in the study had weekly permeability tests until discharge, but repeat testing was not done in 40 children $(26.8 \%)$ due to early death in 15 , being taken from hospital before discharge (absconded) in 23 , or refused consent in two.

The present study followed a one year pilot study in this setting with a $40 \%$ failure rate of L-R tests with daytime five hour urine collection. The anorexia and oliguria of children with kwashiorkor meant that a longer urine collection period was necessary, but it was difficult to keep urine bags on for longer daytime collection. Since this is easier during sleep, we changed to overnight urine collection, and were able to reduce the failure rate of testing to $6.2 \%$ (23/370 tests). The mean duration (95\% confidence interval, CI) of overnight urine collection was longer at 7.6 hours $(7.4$ to 7.7) than with daytime testing. Mean overnight urine volumes were lower at $70 \mathrm{ml}$ (65 to 75$)$ and urea concentrations higher at $31.7 \mathrm{mmol} / 1$ (27.9 to 36.1 ) than with daytime tests (volumes

Table 1 Baseline comparison of malnutrition cases and hospital controls

\begin{tabular}{|c|c|c|c|}
\hline Mean $(95 \%$ CI) or No (\%) & Kwashiorkor cases $(n=149)$ & Controls $(n=45)$ & ANOVA p value \\
\hline Age (months) ${ }^{\star}$ & 28.3 (26.7 to 29.9$)$ & $28.6(22.5$ to 36.3$)$ & 0.88 \\
\hline Male sex & $116(78)$ & $23(51)$ & 0.001 \\
\hline Distance ( $\min$ ) to hospital & $60.3(54.1$ to 66.8$)$ & $59.8(42.5$ to 84.3$)$ & 0.98 \\
\hline Family size & $4.7(4.4$ to 5.0$)$ & $5.2(4.7$ to 5.9$)$ & 0.07 \\
\hline Still breast fed & $8(5.4)$ & $18(40)$ & 0.00001 \\
\hline Socioeconomic status score $\nmid$ & $14.8(14.1$ to 15.5$)$ & $17.5(15.8$ to 19.1$)$ & 0.001 \\
\hline Mothers' schooling (years) & $3.3(2.9$ to 3.8$)$ & $4.0(2.6$ to 6.4$)$ & 0.21 \\
\hline Fathers' schooling (years) & $6.2(5.6$ to 6.9$)$ & $7.6(6.6$ to 8.8$)$ & 0.06 \\
\hline Wasting (WHZ) & $-1.98(-1.80$ to -2.15$)$ & $-0.18(0.20$ to -0.57$)$ & 0.0000001 \\
\hline Stunting (HAZ) & $-3.52(-2.94$ to -3.73$)$ & $-2.38(-1.98$ to -2.78$)$ & 0.001 \\
\hline Urine volume for L-R test $(\mathrm{ml})^{\star}$ & $65.3(58.1$ to 73.5$)$ & $96.8(81.8$ to 114.6$)$ & 0.001 \\
\hline Mean L-rhamnose recovery $(\%)^{\star}$ & $1.04(0.85$ to 1.28$)$ & $2.54(1.85$ to 3.49$)$ & 0.0002 \\
\hline Mean lactulose recovery $(\%)^{\star}$ & $0.164(0.145$ to 0.187$)$ & $0.162(0.114$ to 0.231$)$ & 0.95 \\
\hline L-R ratio ${ }^{\star}$ & $17.3(15.0$ to 19.8$)$ & $7.0(5.6$ to 8.7$)$ & 0.000001 \\
\hline
\end{tabular}

$\star$ Geometric means.

+ Higher score for higher socioeconomic status.

ANOVA = analysis of variance; HAZ = height/age $\mathrm{z}$ score; WHZ = height/weight $\mathrm{z}$ score. 


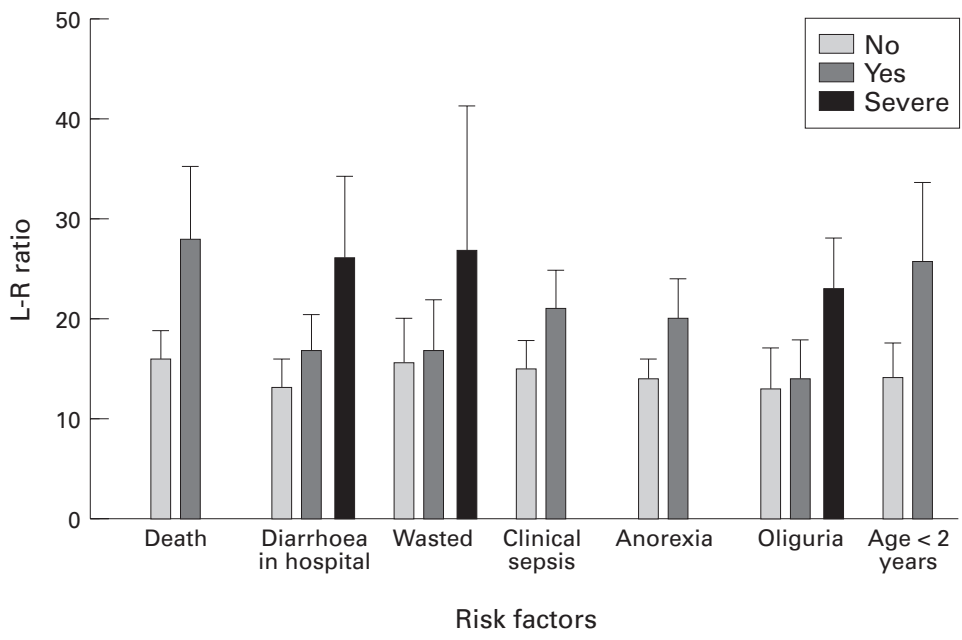

Figure 1 Risk factors for abnormally high L-R ratios in 149 kwashiorkor cases. The severe categories for diarrhoea in hospital, wasting, and oliguria were predefined as diarrhoea for $>50 \%$ of hospital days $(n=30)$, weight/height below $3 \mathrm{NCHS} z$ scores $(n=37)$, and urine output $<0.5 \mathrm{ml} / \mathrm{kg} / \mathrm{hour}(n=29)$.

$=155 \mathrm{ml}, 130$ to $179 ;$ urea $=22.4 \mathrm{mmol} / 1,19.7$ to $26.1 ; \mathrm{n}=128$ ).

Lactulose and L-rhamnose in urine were measured by thin layer chromatography. This was done initially in Malawi, but due to difficulties in separating lactulose from lactose, the specimens were sent to Menzies' laboratory at King's College, London, where lactulose, lactose, and L-rhamnose levels in urine were measured by thin layer chromatography by a previously reported technique. ${ }^{17}{ }^{18}$ After oral administration, mean urinary recoveries in normal subjects at 5 hours are approximately $0.25 \%$ for lactulose and $10 \%$ for L-rhamnose, giving a normal L-R ratio of about $0.025 .{ }^{19} \mathrm{We}$ have multiplied this ratio by 100 to give a convenient value, so that an L-R ratio previously expressed as 0.025 now becomes 2.5 . The normal L-R ratio by this technique with an isotonic test sugar solution is 2.7 (95\% CI 0.8 to 5.2) for developed countries. This compares with mean ratios ranging from 3.4 to 9.6 for 'healthy' controls in African countries and 24.4 (13.7 to 35.1) for untreated coeliac disease.

DATA ANALYSIS

Data were entered and analysed using version 6 of Epi-Info (Centers for Disease Control/ World Health Organisation) on a portable computer and anthropometric $\mathrm{z}$ scores calculated using Epinut. Variables which were not

Table 2 Logistic regression for death and diarrhoea

\begin{tabular}{lllll}
\hline Dependent variable & Independent variable & Odds ratio & $95 \% C I$ & p value \\
\hline 1. Death & Rhamnose absoption & 0.04 & 0.01 to 0.15 & $<0.001$ \\
& Lactulose permeation & 17.4 & 5.4 to 56.1 & $<0.001$ \\
& Maize diet (v milk) $\dagger$ & 3.7 & 1.6 to 8.3 & 0.002 \\
& Younger age & 16.1 & 2.2 to 118.4 & 0.006 \\
& Diarrhoeal burden & 2.8 & 1.2 to 6.9 & 0.021 \\
& Rash severity & 1.6 & 1.0 to 2.4 & 0.031 \\
2. Diarrhoea & Wasting severity (WHZ) & 1.5 & 1.0 to 2.2 & 0.045 \\
& Rhamnose absorption & 0.27 & 0.2 to 0.9 & $<0.001$ \\
& Lactulose permeation & 5.1 & 2.4 to 10.7 & $<0.001$ \\
& Milk diet (v maize) $\dagger$ & 4.8 & 2.7 to 8.6 & $<0.001$ \\
& Oedema severity & 1.6 & 1.3 to 2.0 & $<0.001$ \\
\hline
\end{tabular}

^ Log values.

+ See companion paper for explanation of diets.

Diarrhoeal burden $=$ proportion of hospital days with diarrhoea

$\mathrm{WHZ}=$ weight $/$ height $\mathrm{z}$ scores. normally distributed, such as L-R ratio, were $\log$ transformed for analyses and are presented as a geometric mean and $95 \% \mathrm{CI}$. For normally distributed variables with homogeneity of variance (Bartlett's test), means were compared by $t$ tests, one way analysis of variance or the odds ratio with $95 \% \mathrm{CI} ; \mathrm{p}$ values are $\chi^{2}$ for frequency counts and $t$ tests for measurements. Multiple linear regression was performed using EpiInfo, and logistic regression using GLIM (Generalized Linear Interactive Modelling) and Egret. Graphs were constructed using GraphPad PRISM version 2. Ethical approval of the study was granted by the Health Sciences Research Committee of Malawi.

\section{Results}

We carried out 347 L-R permeability tests in 194 hospitalised children, including 149 with kwashiorkor and 45 controls. Repeat testing was done a week later in 109 kwashiorkor cases $(73.2 \%)$ and another 44 tests on the third or fourth week. Table 1 compares kwashiorkor cases to controls on admission, showing expected differences in sex, breast feeding, socioeconomic status, and nutritional status. Although there was a male predominance (2.5:1) of kwashiorkor cases studied, mean L-R ratios in boys were 15.8 (14.1 to 17.9$)$ compared with girls 15.1 (12.2 to 18.7). L-R ratios were paradoxically higher for children from families in the top $20 \%$ of socioeconomic status $(23.9,18.5$ to 31.0$)$ and with over 8 years of maternal schooling (23.4, 14.8 to 36.9), but these variables were not significant on multiple regression of $\mathrm{L}-\mathrm{R}$ ratios.

Mean L-R ratios (95\% CI) for all 149 kwashiorkor cases on admission was 17.3 (15.0 to 19.8) compared with 7.0 (5.6 to 8.7) for controls $(p<0.000001)$. Although 32 kwashiorkor cases $(21.5 \%)$ had 'normal' permeability ratios for this population (5.6 to 8.7) on admission, the repeat ratio after one week of treatment deteriorated in half of them to a mean of 17.1 (14.6 to 20.1). A history of persistent diarrhoea before admission was elicited in $33.8 \%$ of kwashiorkor cases, but did not affect mean L-R ratios on admission compared with those without such a history (17.1 $v$ 17.7). In contrast, an increased duration or severity of diarrhoea in hospital was associated with worse permeability ratios (fig 1). Mean L-R ratios for kwashiorkor complicated by clinical sepsis were higher (18.2 v 13.0, $\mathrm{p}=0.009)$, and remained significant when controlled for diarrhoea $(\mathrm{F}=7.1, \mathrm{p}<0.005)$. A multiple regression model for intestinal permeability $(\mathrm{F}=24.5$, $\mathrm{p}<0.005$ ), which explained $33.6 \%$ of the variance, had the following significant independent variables (partial $\mathrm{F}$ tests) for higher L-R ratios: oliguria (31.5), severe diarrhoea (17.4), death (16.4), treatment with a maize diet (11.0), young age (10.1), and wasting (4.1).

Differences in mean L- $\mathrm{R}$ ratios between kwashiorkor and controls were due to higher L-rhamnose absorption in controls. But in kwashiorkor, the combination of increased lactulose permeation and decreased L-rhamnose absorption was associated with a higher risk of 


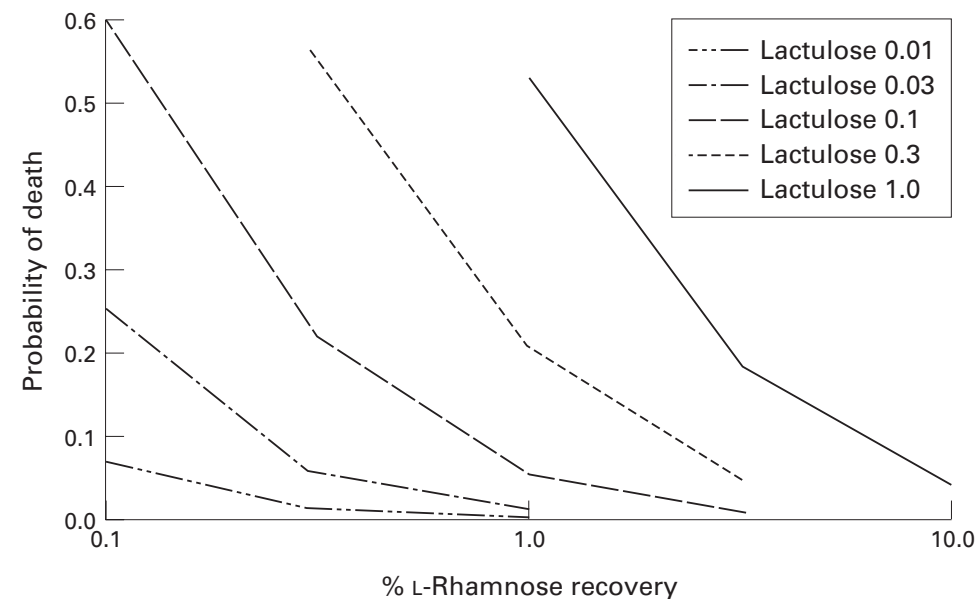

Figure 2 The higher probability of death with decreasing L-rhamnose absorption at different lactulose permeation rates. Note the logarithmic scale for lactulose and L-rhamnose. This illustrates the inverse ratio of L-rhamnose and lactulose permeation in kwashiorkor, which is consistent with villous atrophy.

mortality (fig 2) and also a higher prevalence of diarrhoea. Wasting, on the other hand, was only associated with L-rhamnose malabsorption $(p=0.005)$. Finally, mean L-R ratios showed a slow non-significant $(p=0.22)$ weekly improvement with nutritional rehabilitation from 16.3 (14.0 to 19.0 ) on admission to 13.3 (11.1 to 15.9$)$ and 14.4 (11.0 to 18.8$)$.

\section{Discussion}

PERMEABILITY IN KWASHIORKOR

In this first study to focus on intestinal permeability in kwashiorkor, we found permeability ratios of $>10$ on admission in 110 kwashiorkor cases $(73.2 \%)$, indicative of mucosal damage. Kwashiorkor is known from biopsy studies to be associated with villous atrophy, decreased villous-crypt ratio and increased cellularity of the lamina propria. ${ }^{20-22}$ Although severe mucosal injury occurs in only a proportion of malnourished children, it is more common in kwashiorkor, possibly due to the effect of protein depletion on mucosal recovery. ${ }^{23}$ An Ethiopian study of 17 children with kwashiorkor documented abnormal D-xylose tolerance and carbohydrate malabsorption in a high proportion of cases. ${ }^{24}$ The mean L-R ratios in

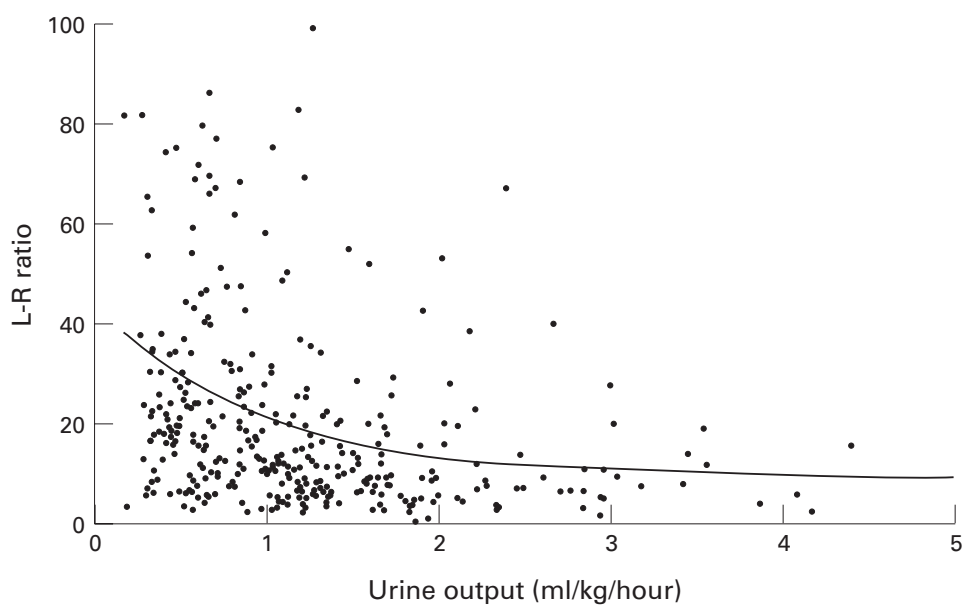

Figure 3 Scatter graph of permeability ratios to urine output during testing for all 347 $L-R$ tests. Oliguria was a marker for anorexia and severity of disease. our kwashiorkor subjects were still lower than those reported for acute gastroenteritis (43, CI 26 to 60) but higher than for persistent diarrhoea in the UK $(12,8$ to 16$)$ by the same technique. ${ }^{9}{ }^{19}$ The explanation for the rise in $\mathrm{L}-\mathrm{R}$ ratio in those with low ratios on admission is unclear, but it corresponded to nosocomial infection and clinical deterioration.

Malawian control children also had abnormal mean L-R ratios (7.0, 5.6 to 8.7 ) compared with UK control children $(2.7,0.8$ to 5.2) using the same test solution and laboratory. ${ }^{19}$ Only eight cases of kwashiorkor $(5.4 \%)$, and nine controls $(20 \%)$ in this study had L-R ratios in the normal range for UK children. This is a feature of the tropical enteropathy syndrome, with small intestinal mucosal damage from overexposure to enteric pathogens in a contaminated environment, often with small bowel bacterial overgrowth. ${ }^{25-27}$ A study in beagles found small intestinal bacterial overgrowth was associated with abnormal permeability in spite of normal gut histology. ${ }^{28}$ Permeability testing is obviously a more sensitive indicator of subtle or patchy mucosal abnormalities than morphometry. The persisting abnormal permeability after clinical recovery in our kwashiorkor cases cannot be explained as tropical enteropathy syndrome, since mean ratios were much higher (14.4 v 7.0).

A notable feature of intestinal permeability in the present study was its prognostic value in kwashiorkor. Both decreased L-rhamnose recovery (malabsorption) and increased lactulose recovery (impaired barrier function) were independent predictors of mortality on logistic regression (table 2). Malabsorption of L-rhamnose with increased lactulose permeation is typical of the permeability changes with villous atrophy. The main permeability difference between kwashiorkor cases and controls in this study was decreased mean L-rhamnose absorption (table 1), which is thought to reflect villous shortening with loss of absorptive surface due to malnutrition. This is confirmed by the strong correlation $(\mathrm{p}=0.005)$ between the severity of L-rhamnose malabsorption and wasting (weight/height $\mathrm{z}$ scores).

Abnormal permeability was also associated with three severity of illness factors: oliguria, sepsis, and diarrhoeal severity. Oliguria was measured as urine output (in $\mathrm{ml} / \mathrm{kg} /$ hour) during overnight testing. Figure 3 shows the rise in L-R ratios at low urine outputs. This was not just a technical problem with the test, but reflected the degree of anorexia due to severe illness. Children with a low urine output during testing (oliguria) had a significantly higher mortality, longer hospital stay and more severe rash. Oliguria was not from dehydration, and was not associated with diarrhoea on the day of testing $(p=0.7)$. Nor was it due to incomplete urine collection because we developed a urine collection protocol (after 12 months of failure) which made incomplete collection unlikely. Moreover, oliguria was associated with a higher urine urea concentration (41.9 $v 26.4 \mathrm{mmol} / \mathrm{l}$, 


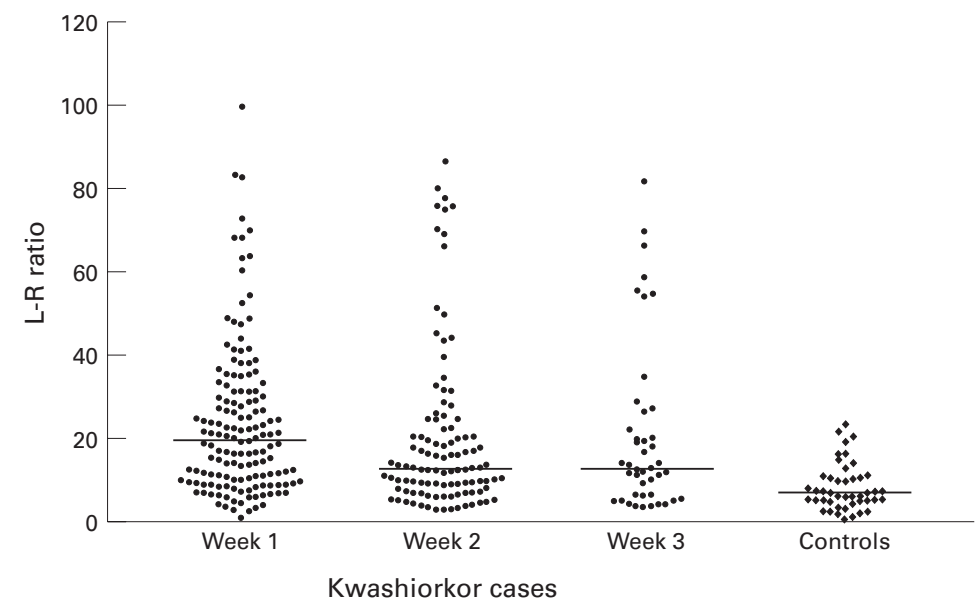

Figure 4 Scatter graph of weekly $L-R$ ratios with nutritional rehabilitation compared with controls. The horizontal lines are median values.

$\mathrm{p}=0.004)$ and had too poor a prognosis to be explained as simply incomplete urine collection.

It is difficult in clinical studies to separate the effects of malnutrition from infection on the intestinal mucosa. Diarrhoea was present in hospital in $83.9 \%$ of our cases with a mean duration of 4.6 days (4.1 to 5.2). Abnormal intestinal permeability correlated highly with diarrhoea, including its presence on the day of testing, its severity (frequency/day) and its duration in hospital, and affected both lactulose and rhamnose permeation. This is consistent with the view that nosocomial diarrhoea in malnutrition affects both mucosal barrier and absorptive functions, whereas malnutrition itself (wasting) affects mainly absorption.

The abnormal permeability associated with clinical sepsis in this study is notable because of studies on bacterial translocation. Abnormal intestinal permeability is a feature of bacterial translocation in malnourished adult patients with multiorgan failure secondary to trauma, sepsis or burns. ${ }^{29-33}$ The high rates of nosocomial sepsis in kwashiorkor ${ }^{34-36}$ are consistent with evidence that protein malnutrition predisposes to gut origin sepsis. ${ }^{37}$ This offers the hope that dietary or other treatment measures which improve gut permeability in kwashiorkor may lower sepsis and case fatality rates.

The relationships between intestinal permeability, AIDS and socioeconomic status in our kwashiorkor cases were puzzling. Mean L-R ratios for the 50 ELISA tested cases were 18.2 (13.3 to 24.9 ) for positives compared with 24.0 (18.0 to 32.1) for negatives. The remaining 99 untested cases had L-R ratios of 18.2 (9.9 to 33.5) for those with probable AIDS by the clinical protocol compared with 15.4 (12.8 to 18.4) for those not suspected of AIDS. We interpret this to mean that clinical status or severity of disease predicted abnormal permeability better than HIV status, since the difference between tested negative and untested unsuspected cases reflected the degree of sickness and response to nutritional rehabilitation. Mean socioeconomic scores for AIDS cases with kwashiorkor was 16.0 (4.8 to 17.3 ) compared with 14.4 (3.5 to 15.2 ) for negative cases, with no difference whether diagnosed by ELISA test or clinical protocol. The paradox of higher mean L-R ratios in kwashiorkor with parents of higher socioeconomic and educational levels $(p<0.005)$ is explained by AIDS, since it was clinically obvious that AIDS was a more likely cause of malnutrition in these families than in those living in dire poverty.

PERMEABILITY TESTING

The dual sugar test is ideally suited for assessing the small intestine in children with severe malnutrition and diarrhoea, and has important advantages of non-invasiveness, repeatability, and reliability. Malnutrition may affect intestinal function by a decrease in absorptive surface area without decreasing villous height or causing other structural changes. ${ }^{38}$

The main problem with permeability testing on urine in sick young children, which is not overcome by using two probes, is that they cannot be relied upon to void at the end of a five hour urine collection, so the timed collection would in fact be shorter than the prescribed five hours. Permeation rates of test sugars differ between jejunum and ileum, so urine collections shorter than five hours would give falsely low ratios. ${ }^{39}$ Although urine collection difficulties in children are well known, this issue has been largely ignored in paediatric permeability studies, possibly because most subjects in developed countries have been older children. We overcame the problems of prolonged urine collection by using overnight collection with urine bags and a special skin adhesive technique. It is unfortunate that the many different methods of dual sugar testing make it difficult to compare results with test sugars of different composition, proportions, or osmolality. ${ }^{11}$

Finally, in spite of clinical recovery, mean $\mathrm{L}-\mathrm{R}$ ratios did not return to control values in this study. Only 14 of 44 L-R tests $(31.8 \%)$ had fallen to a ratio of $<10$ after $3-4$ weeks of nutritional rehabilitation (fig 4). A slow response of the small intestine morphology to nutritional rehabilitation has been noted previously. ${ }^{61-23} 40$ It has been attributed to persisting exposure to intestinal pathogens due to poor hygienic conditions, but our permeability ratios after clinical recovery are much higher than in tropical enteropathy syndrome as seen in control children. It is more likely to be related to defective intestinal cell renewal after enteric infection in the malnourished host. ${ }^{22} 2341$

More research is needed on how to rehabilitate the small intestine more rapidly during treatment of severe malnutrition. The L-R test could be used to compare the effect of different treatment regimens on the rate of recovery of intestinal permeability, as a proxy for mucosal damage. This would assist the development of improved case management protocols for severe malnutrition in developing countries, and is the subject of the companion paper. 


\section{Key messages}

- Kwashiorkor still has a 30\% case fatality rate at urban hospitals in Malawi

- Intestinal permeability can be measured non-invasively by the lactuloserhamnose test as an indicator of gut damage

- The degree of abnormal permeability in kwashiorkor reflects the severity of illness and improves only slowly with nutritional rehabilitation

- Changes in intestinal permeability can be used to evaluate treatment interventions

We would like to thank Professor John D Mathews of the Menzies School of Health Research, Darwin, Australia for statistical assistance; Rosemary Warden of the University of Newcastle, Australia for nutritional advice; Henry Kamanga of the College of Medicine in Malawi, Cassandra Arnold of the University of Newcastle and Roger Crane of King's College in London for laboratory assistance, and Janssen-Cilag, Australia for supplying the Duphalac.

1 Anonymous. Malawi demographic and health survey, 1992. Zomba: Malawi Government, 1994.

2 Anonymous. World development report 1995. Oxford: Oxford University, 1995.

3 Waterlow JC. Protein-energy malnutrition. London: Edward Arnold, 1992:64-86.

4 van Elburg RM, Uil JJ, Kokke FTM, Mulder CJJ, Heymans HSA. Repeatability of the sugar-absorption test, using lac-
tulose and mannitol, for measuring intestinal permeability for sugars. $\mathcal{F}$ Pediatr Gastroenterol Nutr 1995;20:184-8.

5 Travis S, Menzies I. Intestinal permeability: functional assessment and significance. Clin Sci 1992;82:471-88.

6 Sullivan PB, Lunn PG, Northrop Clewes C, Crowe PT Marsh MN, Neale G. Persistent diarrhea and malnutrition - the impact of treatment on small bowel structure and permeability. $\mathcal{F}$ Pediatr Gastroenterol Nutr 1992;14:208-15.

7 van Elburg RM, Uil JJ, de Monchy JG, Heymans HS. Intestinal permeability in pediatric gastroenterology. Scand $\mathcal{F}$ Gastroenterol Suppl 1992;194:19-24.

8 Hamilton I, Hill A, Bose B, Bouchier IA, Forsyth JS. Small intestinal permeability in pediatric clinical practice. $\mathcal{F}$ Pediatr Gastroenterol Nutr 1987;6:697-701.

9 Ford RP, Menzies IS, Phillips AD, Walker-Smith JA, Turner M. Intestinal sugar permeability: relationship to diarrhoeal disease and small bowel morphology. F Pediatr Gastroenterol Nutr 1985;4:568-74.

10 Akinbami FO, Brown GA, McNeish AS. Intestinal permeability as a measure of small intestinal mucosal integrity: correlation with jejunal biopsy. Afr F Med Med Sci 1989;18 187-92.

11 Peeters M, Hiele M, Ghoos Y, et al. Test conditions greatly influence permeation of water soluble molecules through the intestinal mucosa: need for standardisation. Gut 1994 35:1404-8.

12 Bjarnason I, Macpherson A, Hollander D. Intestinal permeability: an overview. Gastroenterology 1995;108:156681.

13 Anonymous. Intestinal permeability. Lancet 1985;i:256-8.

14 Crissinger KD, Kvietys PR, Granger DN. Pathophysiology of gastrointestinal mucosal permeability. F Intern Med Suppl 1990;732:145-54.

15 Dibley MJ, Staehling N, Nieburg P, Trowbridge FL. Interpretation of $\mathrm{Z}$-score anthropometric indicators deInterpretation of $Z$-score anthropometric indicators de-
rived from the international growth reference. Am $\mathcal{F}$ Clin Nutr 1987;46:749-62.

16 Brewster DR, Manary MJ, Menzies IS, Henry RL, O'Loughlin EV. Comparison of milk and maize based diets in kwashiorkor. Arch Dis Child 1997;76:242-8.
17 Menzies IS. Quantitative estimation of sugars in blood and urine by paper chromatography using direct densitometry. urine by paper chromatography

18 Teahon K, Smethurst P, Levi AJ, Menzies IS, Bjarnason I. Intestinal permeability in patients with Crohn's disease and their first degree relatives. Gut 1992;33:320-3.

19 Noone C, Menzies IS, Banatvala JE, Scopes JW. Intestinal permeability and lactose hydrolysis in human rotaviral gastroenteritis assessed simultaneously by non-invasive differential sugar permeation. Eur f Clin Invest 1986;16:217-25.

20 Brunser O, Reid A, Monckeberg F, Maccioni A, Contreras I. Jejunal mucosa in infant malnutrition. Am 7 Clin Nutr 1968;21:976-83.

21 Stanfield JP, Hutt MSR, Tunnicliffe R. Intestinal biopsy in kwashiorkor. Lancet 1965;ii:519-23.

22 Bhan MK The gut in malnutrition. In: Walker WA, Durie PR, Hamilton JR, Walker-Smith JA, Watkins JB, eds. Pediatric gastrointestinal diseases: pathophysiology, diagnosis, management. 2nd Ed. St Louis: Mosby, 1996:867-78.

23 Viteri FE, Flores JM, Alvarado J, Behar M. Intestinal malabsorption in malnourished children before and during recovery. Relation between severity of protein deficiency and the malabsorption process. Am F Dig Dis 1973;18:20111.

24 Habte D, Hyvarinen A, Sterky G. Carbohydrate malabsorption in kwashiorkor. Ethiop Med f 1973;11:33-40.

25 Lindenbaum J, Harmon JW, Gerson CD. Subclinical malabsorption in developing countries. Am f Clin Nutr 1972;25:1056-61.

26 Chacko CJ, Paulson KA, Mathan VI, Baker SJ. The villus architecture of the small intestine in the tropics: a necropsy study. F Pathol 1969;98:146-51.

27 Henry FJ, Patwary Y, Huttly SR, Aziz KM. Bacterial contamination of weaning foods and drinking water in rural contamination of weaning foods and drinking

28 Morris TH, Sorensen SH, Turkington J, Batt RM. Diarrhoea and increased intestinal permeability in laboratory beagles associated with proximal small intestinal bacterial overgrowth. Lab Anim 1994;28:313-9.

29 Deitch EA. Bacterial translocation: the influence of dietary variables. Gut 1994;35:S23-7.

30 Deitch EA, Xu DZ, Qi L, Specian RD, Berg RD. Protein malnutrition alone and in combination with endotoxin impairs systemic and gut-associated immunity. fournal of Parenteral and Enteral Nutrition 1992;16:25-31.

31 Deitch EA. The role of intestinal barrier failure and bacterial translocation in the development of systemic infection and multiple organ failure. Arch Surg 1990;125: 403-4.

32 Deitch EA. Bacterial translocation: is it of clinical significance? Gastroenterology 1990;98:243-4

33 Deitch EA. Bacterial translocation of the gut flora. F Trauma 1990;30:S184-9.

34 Christie CD, Heikens GT, McFarlane DE. Nosocomial and community-acquired infections in malnourished children. f Trop Med Hyg 1988;91:173-80.

35 Brown $\mathrm{KH}$, Gilman RH, Gaffar $\mathrm{A}$, et al. Infections associated with severe protein-calorie malnutrition in hospitalized infants and children. Nutr Res 1981;1:33-46.

36 Berkowitz FE. Bacteremia in hospitalized black South African children: a one year study emphasizing nosocomial bacteremia and bacteremia in malnourished children. $A m \mathcal{F}$ Dis Child 1984;138:551-6.

37 Deitch EA, Ma WJ, Ma L, Berg RD, Specian RD. Protein malnutrition predisposes to inflammatory-induced gutmalnutrition predisposes to inflammatory-in
origin septic states. Ann Surg 1990;211:560-7.

38 da Costa Ribeiro H, Teichberg S, McGarvey E, Lifshitz F. Quantitative alterations in the structural development of jejunal absorptive epithelial cells and their subcellular organelles in protein-energy malnourished rats: a stereologic analysis. Gastroenterology 1987;93:1381-92.

39 Elia M, Behrens R, Northrop C, Wraight P, Neale G. Evaluation of mannitol, lactulose and $51 \mathrm{Cr}$-labelled ethylenediaminetetra-acetate as markers of intestinal permeability in man. Clin Sci 1987;73:197-204.

40 Heyman M, Boudraa G, Sarrut S, et al. Macromolecular transport in jejunal mucosa of children with severe malnutrition: a quantitative study. $f$ Pediatr Gastroenterol Nutr 1984;3:357-63.

41 Butzner JD, Butler DG, Miniats OP, Hamilton JR. Impact of chronic protein-calorie malnutrition on small intestinal repair after acute viral enteritis: a study in gnotobiotic piglets. Pediatr Res 1985;19:476-481. 